\title{
Echocardiography in pediatric pulmonary hypertension
}

\section{Pei-Ni Jone* and D. Dunbar Ivy}

Pediatric Cardiology, Children's Hospital Colorado, University of Colorado School of Medicine, Aurora, CO, USA

\section{Edited by:}

Antonio Francesco Corno, Universiti

Sains Malaysia, Malaysia

Reviewed by:

Jeffrey Feinstein, Stanford University, USA

Cecile Tissot, The University

Children's Hospital, Switzerland

Tilman Humpl, SickKids Hospital,

Canada

\section{${ }^{*}$ Correspondence:}

Pei-Ni Jone, Pediatric Cardiology,

Children's Hospital Colorado,

University of Colorado School of

Medicine, 13123 East 16th Avenue,

B100, Aurora, CO 80045, USA

e-mail:pei-ni.jone@

childrenscolorado.org
Pulmonary hypertension $(\mathrm{PH})$ can be a rapidly progressive and fatal disease. Although right heart catheterization remains the gold standard in evaluation of $\mathrm{PH}$, echocardiography remains an important tool in screening, diagnosing, evaluating, and following these patients. In this article, we will review the important echocardiographic parameters of the right heart in evaluating its anatomy, hemodynamic assessment, systolic, and diastolic function in children with $\mathrm{PH}$.

Keywords: pediatric pulmonary hypertension, echocardiography, right heart, right ventricular function

\section{INTRODUCTION}

Pulmonary hypertension $(\mathrm{PH})$ is a progressive disease that carries high morbidity and mortality. Although cardiac catheterization is used to define $\mathrm{PH}$, echocardiography is the most important noninvasive tool that is used to detect $\mathrm{PH}$ (1). It provides the anatomy of the right heart, non-invasive hemodynamic assessment, systolic and diastolic evaluation of the right heart, and serial follow-up for this patient population. A diagnostic classification has been developed and modified at the World Symposiums on Pulmonary Hypertension (WSPH). Initially developed at the second WSPH in Evian (France) in 1998, this clinical classification system identifies five categories of disorders that cause $\mathrm{PH}$, with each group sharing similar hemodynamic, pathologic, and management features; Pulmonary arterial hypertension (PAH) (Group 1); PH due to left heart disease (Group 2); PH due to chronic lung disease and/or hypoxia (Group 3); chronic thromboembolic PH (Group 4); and PH due to multifactorial mechanisms (Group 5) Table 1 (1). Echocardiography is valuable in each of these disorders as will be described. We will further discuss the conventional and advanced echocardiographic evaluation of pediatric $\mathrm{PH}$.

\section{CONVENTIONAL TWO-DIMENSIONAL ECHOCARDIOGRAPHY}

Two-dimensional (2D) echocardiography provides qualitative and quantitative evaluation of the severity of $\mathrm{PH}$.

\section{RIGHT ATRIUM}

The right atrium (RA) dilates over time in patients with $\mathrm{PH}$ and it represents decreased right ventricular (RV) compliance and RV diastolic dysfunction. It is a reservoir for systemic venous return when the tricuspid valve is closed, a passive conduit during early diastole, and active conduit in late diastole (2). Imaging of the RA is easily obtained in the apical four chamber view where RA dimensions of minor and major axis are measured and planimetry of the RA area in end-systole is performed to evaluate for RA dilation (Figure 1) (3). Indexed RA area to body surface area in adult patients with idiopathic $\mathrm{PH}$ has been a predictor of mortality and has been shown to be a prognostic marker for follow up of $\mathrm{PH}$ patients in adults and children (4-6).

\section{INFERIOR VENA CAVA DILATION}

The inferior vena cava (IVC) can be dilated in patients with $\mathrm{PH}$ because of rising RA pressure. It is measured in the subcostal longitudinal view with IVC entering the RA. RA pressure can be estimated by IVC diameter and the presence of inspiratory collapse (7-9). IVC diameter $\leq 2.1 \mathrm{~cm}$ that collapses $>50 \%$ with a sniff suggests a normal RA pressure of $3 \mathrm{mmHg}$ (range, $0-5 \mathrm{mmHg}$ ). IVC diameter $\geq 2.1 \mathrm{~cm}$ that collapses $<50 \%$ with a sniff suggests a high RA pressure of $15 \mathrm{mmHg}$ (range $10-20 \mathrm{mmHg})(3,8,10,11)$. In children, the IVC varies with age of the patient. Elevated RA pressure in children can be assessed on the percentage of collapse of the IVC during inspiration rather than an absolute number.

\section{RIGHT VENTRICLE}

With chronic pressure overload, there is progressive hypertrophy and dilation of the RV. The complex morphology of the RV makes $2 \mathrm{D}$ imaging of the $\mathrm{RV}$ difficult and frequently requires multiple views in the parasternal, apical, and subcostal views to completely evaluate the RV dimensions. However, current recommendation from the guidelines in assessing the right heart includes a standardized imaging of the RV linear dimensions to evaluate for $\mathrm{RV}$ dilation (3). The RV size can be measured from the apical four chamber view at end-diastole in the "RV-focused view" (3, 12). The basal diameter is measured at the level of the tricuspid valve and the mid-cavity diameter is measured at the middle third of the RV at the level of the left ventricular (LV) papillary muscle. The longitudinal dimension is from the plane of the 
Table 1 | Updated classification of pulmonary hypertension.

1. Pulmonary arterial hypertension

1.1 Idiopathic PAH

1.2 Heritable $\mathrm{PAH}$

1.2.1 BMPR2

1.2.2 ALK-1, ENG, SMAD9, CAV1, KCNK3

1.2.3 Unknown

1.3 Drug and toxin induced

1.4 Associated with:

1.4.1 Connective tissue disease

1.4.2 HIV infection

1.4.3 Portal hypertension

1.4.4 Congenital heart diseases

1.4.5 Schistosomiasis

1 ' Pulmonary veno-occlusive disease and/or pulmonary capillary hemangiomatosis

$1 "$. Persistent pulmonary hypertension of the newborn (PPHN)

2. Pulmonary hypertension due to left heart disease

2.1 Left ventricular systolic dysfunction

2.2 Left ventricular diastolic dysfunction

2.3 Valvular disease

2.4 Congenital/acquired left heart inflow/outflow tract obstruction and congenital cardiomyopathies

3. Pulmonary hypertension due to lung diseases and/or hypoxia

3.1 Chronic obstructive pulmonary disease

3.2 Interstitial lung disease

3.3 Other pulmonary diseases with mixed restrictive and obstructive pattern

3.4 Sleep-disordered breathing

3.5 Alveolar hypoventilation disorders

3.6 Chronic exposure to high altitude

3.7 Developmental lung diseases

4. Chronic thromboembolic pulmonary hypertension (CTEPH)

5. Pulmonary hypertension with unclear multifactorial mechanisms

5.1 Hematologic disorders: chronic hemolytic anemia, myeloproliferative disorders, splenectomy

5.2 Systemic disorders: sarcoidosis, pulmonary histiocytosis, lymphangioleiomyomatosis

5.3 Metabolic disorders: glycogen storage disease, Gaucher disease, thyroid disorders

5.4 Others: tumoral obstruction, fibrosing mediastinitis, chronic renal failure, segmental $\mathrm{PH}$

BMPR: bone morphogenic protein receptor type II; CAV1: caveolin-1; ENG: endoglin; HIV: human immunodeficiency virus; PAH: pulmonary arterial hypertension. tricuspid valve annulus to the RV apex (Figure 2). Indexed RV end-diastolic diameter measured just above the tricuspid valve annulus reported by Burgess et al. has been associated with poor prognosis in patients with chronic pulmonary disease in adults (13). RV dilation is an early sign of RV maladaptation to increased pressure overload and an early sign of RV dysfunction (14). This has also been shown in children with PAH although the measurements of RV end-diastolic dimension were measured from the parasternal short axis view from M-mode (6). Future studies are needed in RV basal diameters in children with $\mathrm{PH}$ to evaluate progressive RV dilation which is an early sign of RV dysfunction.

\section{INTERVENTRICULAR SEPTUM}

Right ventricular pressure overload causes flattening of the interventricular septum (IVS) in end-systole into the left ventricle $(\mathrm{LV})$, resulting a "D-shaped" LV in parasternal short axis view. Eccentricity index has been derived from the ratio between the $\mathrm{LV}$ anteroposterior dimension and the septolateral dimension at the level of the papillary muscle (Figure 3) (15). LV deformation of the IVS is greatest in end-systole in patients with RV pressure overload. Eccentricity index is abnormal when the ratio is $>1.0$ and has been shown to correlate well with invasive measurements of pulmonary artery pressure and associated with adverse clinical outcome in adults with $\mathrm{PH}(5,16)$. Serial evaluation of eccentricity index with improvement in this index has been shown in targeted PH therapy in adults (17). The eccentricity index has been shown in children to be worse in patients with idiopathic $\mathrm{PH}$ compared to $\mathrm{PH}$ associated with congenital heart disease (6). Flattening of the IVS can be classified into mild, moderate, or severe depending on the degree of $\mathrm{PH}$ (Figure 3 ). In the absence of tricuspid regurgitation (TR) to estimate RV pressure, septal flattening offers indirect evidence of elevated pulmonary artery pressure. End-systolic flattening of the IVS has proven to be a sensitive marker for RV systolic hypertension in children (18). $\mathrm{RV} / \mathrm{LV}$ ratio at end-systole measured at the level of the papillary muscles incorporates RV dimension in the parasternal short axis view and has been shown to correlate with invasive measures of hemodynamics and RV/LV end-systolic ratio $>1$ is associated with adverse clinical outcomes in children with PH (Figure 4) (19). Flattening of IVS into the LV impairs LV filling. Both the systolic and diastolic volumes are reduced. The importance of ventricularventricular interactions is increasingly recognized in patients with $\mathrm{PH}$ in both adult and pediatric populations $(20,21)$. Interventricular septal shift impairs LV diastolic filling, which results in decreased LV function. In severe PH with severe septal shift, the LV mid-cavity or outflow tract may become obstructed and the cardiac output (CO) can be decreased. $\mathrm{CO}$ can be estimated from echocardiography by the following equation:

$$
\mathrm{CO}=(\text { LVOT diameter } / 2)^{2} \times 3.14 \times \mathrm{VTI}(\text { LVOT }) \times \mathrm{HR}
$$

The LV outflow tract (LVOT) is obtained from the parasternal long axis view and the velocity time integral (VTI) of LVOT is obtained by spectral Doppler from an apical four chamber view tilted anterior to view the LVOT. Cardiac index is calculated by dividing the $\mathrm{CO}$ by the body surface area. 


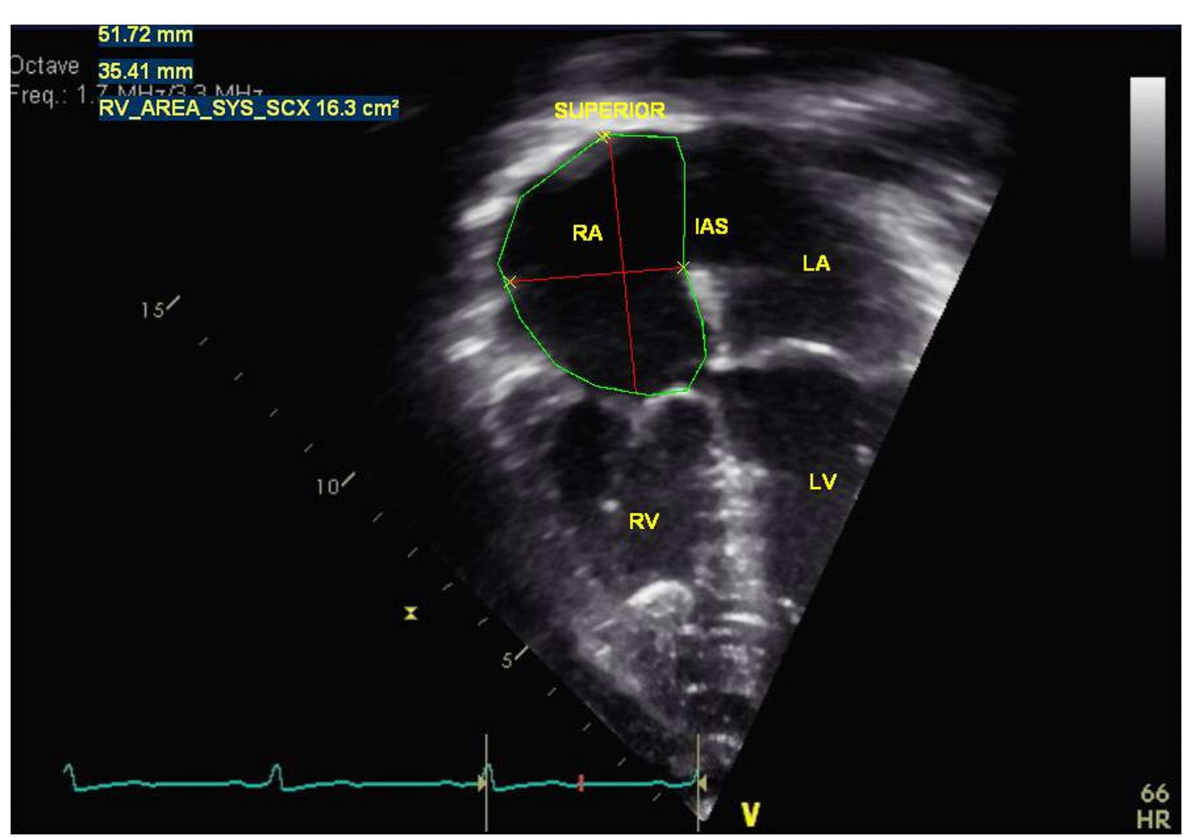

FIGURE 1 | Measurement of right atria dimensions (major and minor axis) and right atrial area in end-systole in a pulmonary hypertension patient. $R A=$ right atria, $R V=$ right ventricle, $I A S=$ interatrial septum, $L A=$ left atria, $L V=$ left ventricle.

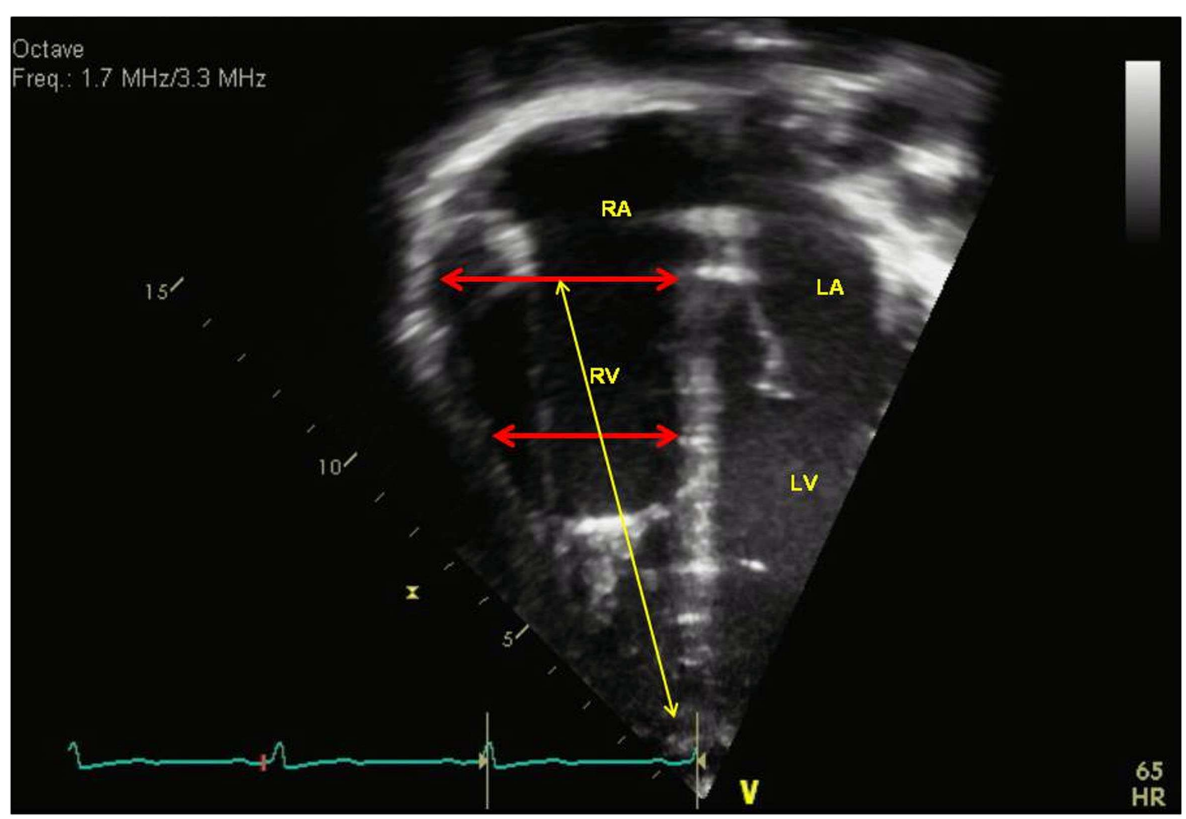

FIGURE 2 | Measurement of right ventricular dimensions in end-diastole with basal dimension at the level of the tricuspid valve, the mid-cavity dimension (red arrows), and longitudinal dimension (yellow arrow). RA = right atria, $R V=$ right ventricle, $L A=l e f t$ atria, $L V=l e f t$ ventricle.

\section{ATRIAL LEVEL SHUNT}

An atrial level shunt is important in patients with $\mathrm{PH}$ as it provides relief to symptoms of severe $\mathrm{PH}$ by increasing systemic flow, reducing RV preload, and increasing $\mathrm{CO}$. Atrial level shunts can be assessed in the parasternal short axis, subcostal short axis, and subcostal long axis views. Contrast echocardiography may also help in the assessment of atrial level shunt. In adults with $\mathrm{PH}$, functional class has been shown to improve with the creation of an atrial level 


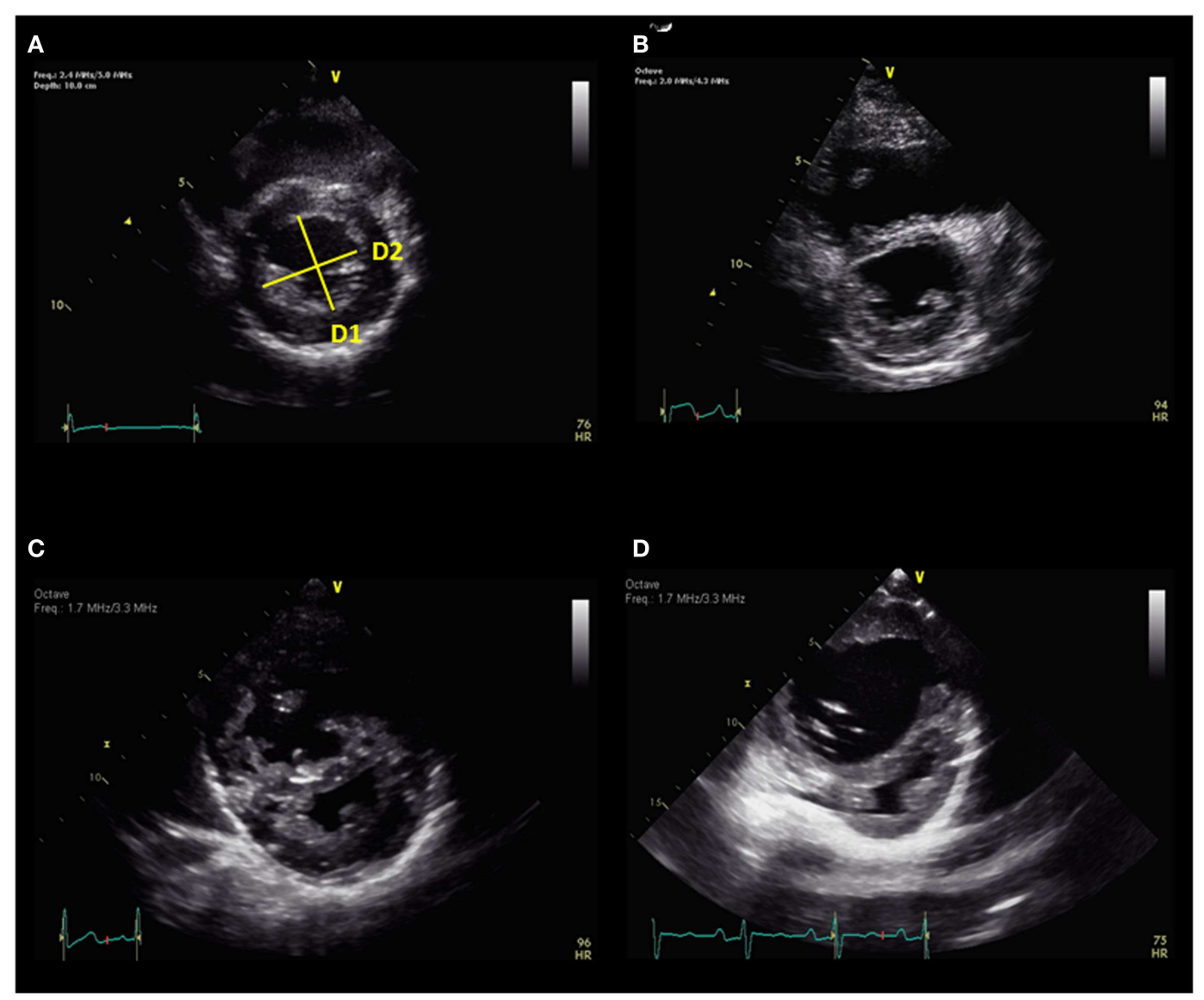

FIGURE 3 | (A) Eccentricity index=D2/D1 and normal septum. There is progressive septal flattening from mild (B), moderate (C), to severe (D) $\mathrm{D} 1=$ diameter $1, \mathrm{D} 2=$ diameter 2.

shunt, which leads to cyanosis from right to left shunting but can increase CO. Some series advocate use of an atrial septostomy to prolong survival $(22,23)$.

\section{PERICARDIAL EFFUSION}

The presence of pericardial effusion is associated with increased risk of poor outcome in adults with $\mathrm{PH}$ but has not been a prognostic indicator for children (5). The size of the pericardial effusion is not predictive of outcome in children. Pericardial thickening and total pericardial score has been developed to score the amount of pericardial effusion seen in patients with PH (24). Increased pericardial thickening and increased pericardial effusion were found to be higher in adults with severe $\mathrm{PH}$.

\section{HEMODYNAMIC ASSESSMENT USING DOPPLER ECHOCARDIOGRAPHY}

\section{SYSTOLIC PULMONARY ARTERY PRESSURE}

The normal TR jet has a maximal velocity of $<2.5 \mathrm{~m} / \mathrm{s}$ (25). The normal estimated systolic pulmonary artery pressure (SPAP) is $\leq 35 \mathrm{mmHg}$ (26). SPAP can be estimated from a peak TR velocity by continuous-wave Doppler using the modified Bernoulli equation in the absence of RV outflow tract (RVOT) obstruction (27). This is the most useful non-invasive method to predict SPAP. The mean RA pressure must be added to the result of the Bernoulli equation to determine the RV systolic pressure (RVSP). In the absence of RVOT obstruction, the SPAP equals the RVSP. The equation is below:

$$
\mathrm{RVSP}=\mathrm{SPAP}=4(\mathrm{TR} \max )^{2}+\text { mean RA pressure }(\mathrm{mRAP})
$$

Estimation of SPAP from the TR jet is dependent on the angle and the presence of the sufficient Doppler envelope (Figure 5). Therefore, it is recommended that the TR is obtained from multiple views (apical four chamber view or parasternal views) until the best Doppler angle and the highest velocity are obtained. Adult studies have shown that this method of estimating SPAP correlates linearly with hemodynamic assessment in cardiac catheterizations $(28,29)$. In pediatric patients with chronic lung disease, this estimate of SPAP using TR velocity has been shown to correctly diagnose the presence or absence of $\mathrm{PH}$ in $79 \%$ of children but was only able to diagnose correctly the severity of $\mathrm{PH}$ in $47 \%$. (30) In a recent prospective trial of pediatric $\mathrm{PH}$ patients using TR to estimate SPAP compared to right heart catheterization, overestimation and underestimation of RV pressure occurred and TR velocity was inaccurate in children with elevated right heart 


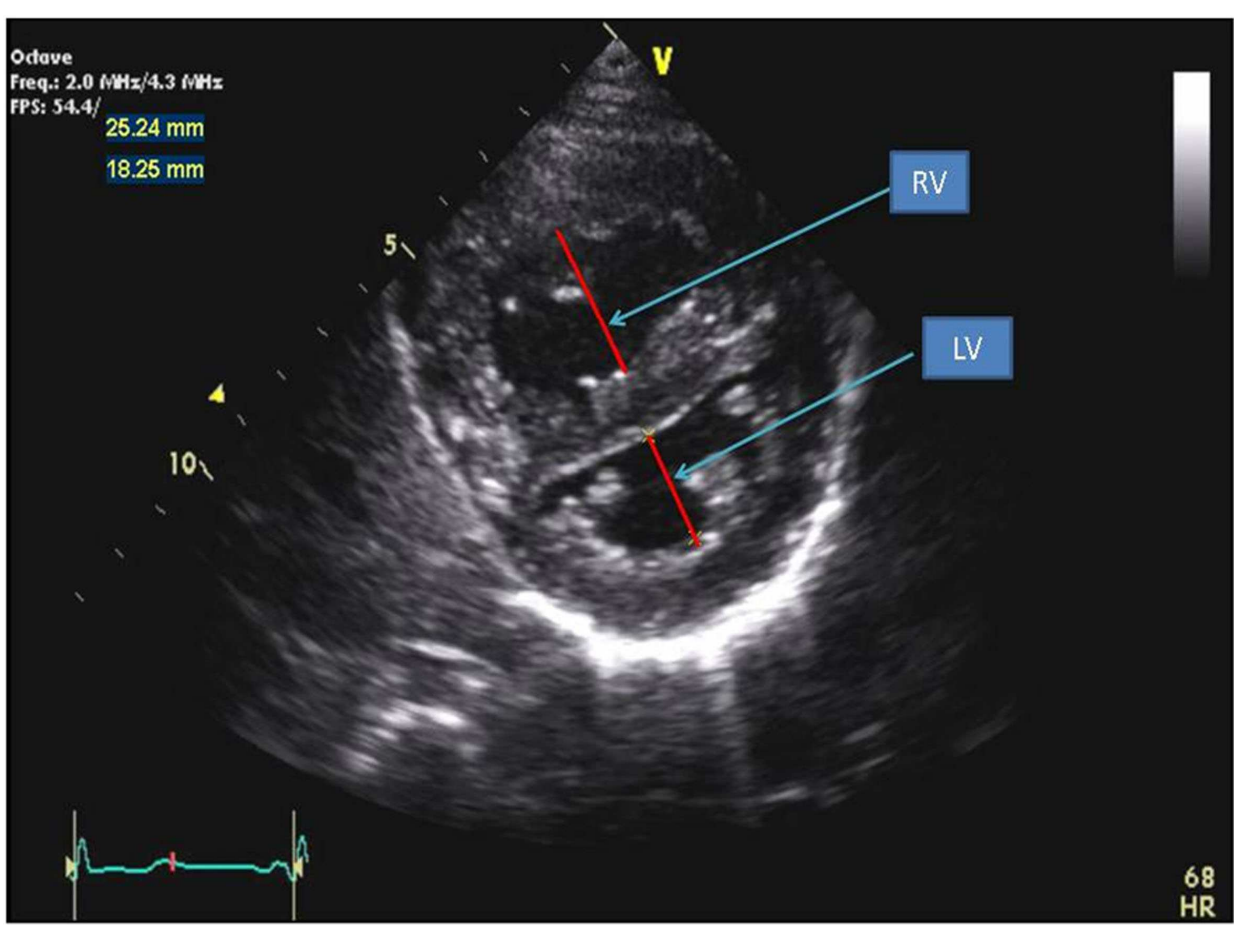

FIGURE 4 | Parasternal short axis view of the right and left ventricles at the level of the papillary muscles. The RV/LV ratio is derived from RV diameter and LV diameter at end-systole.

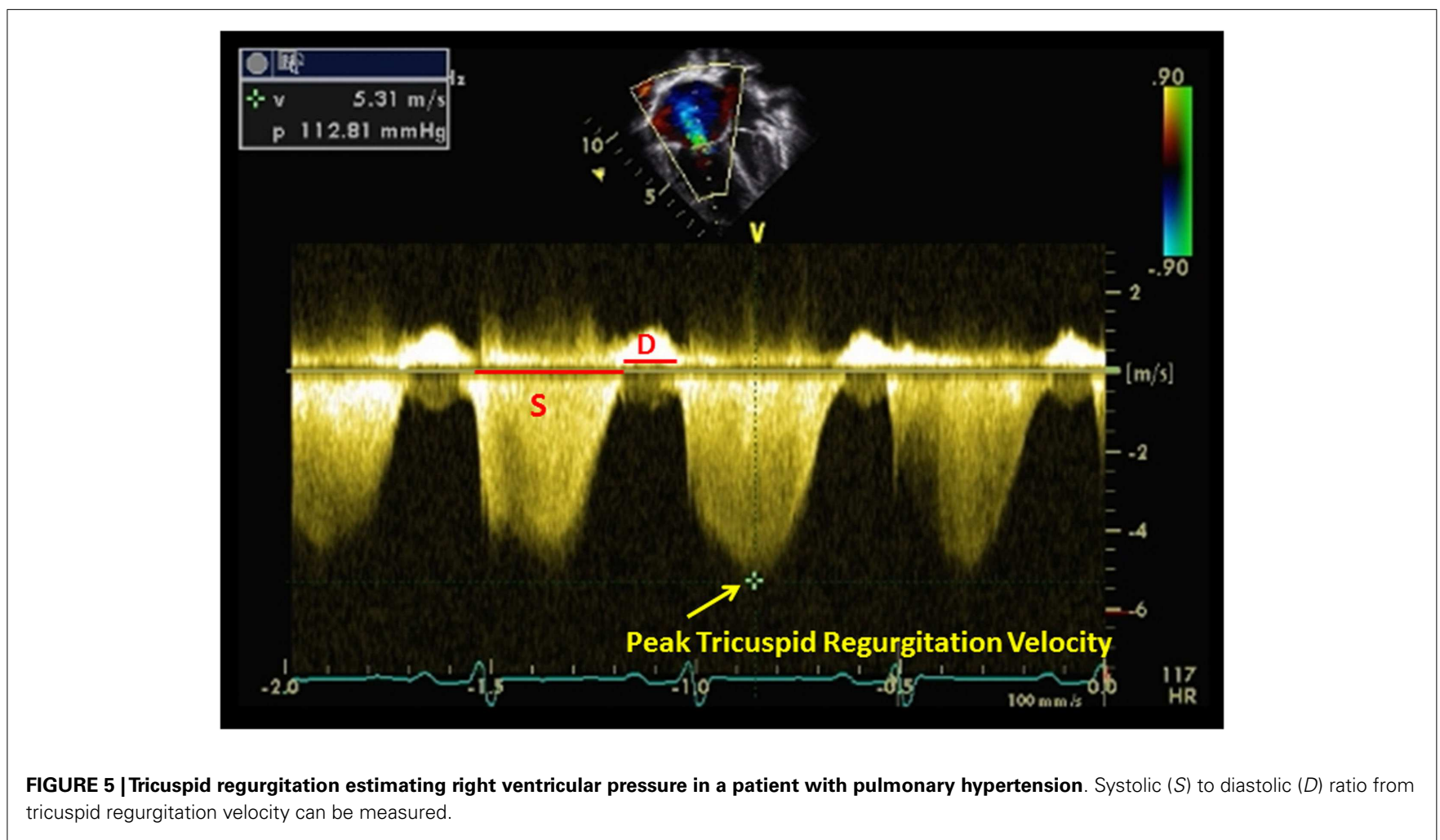




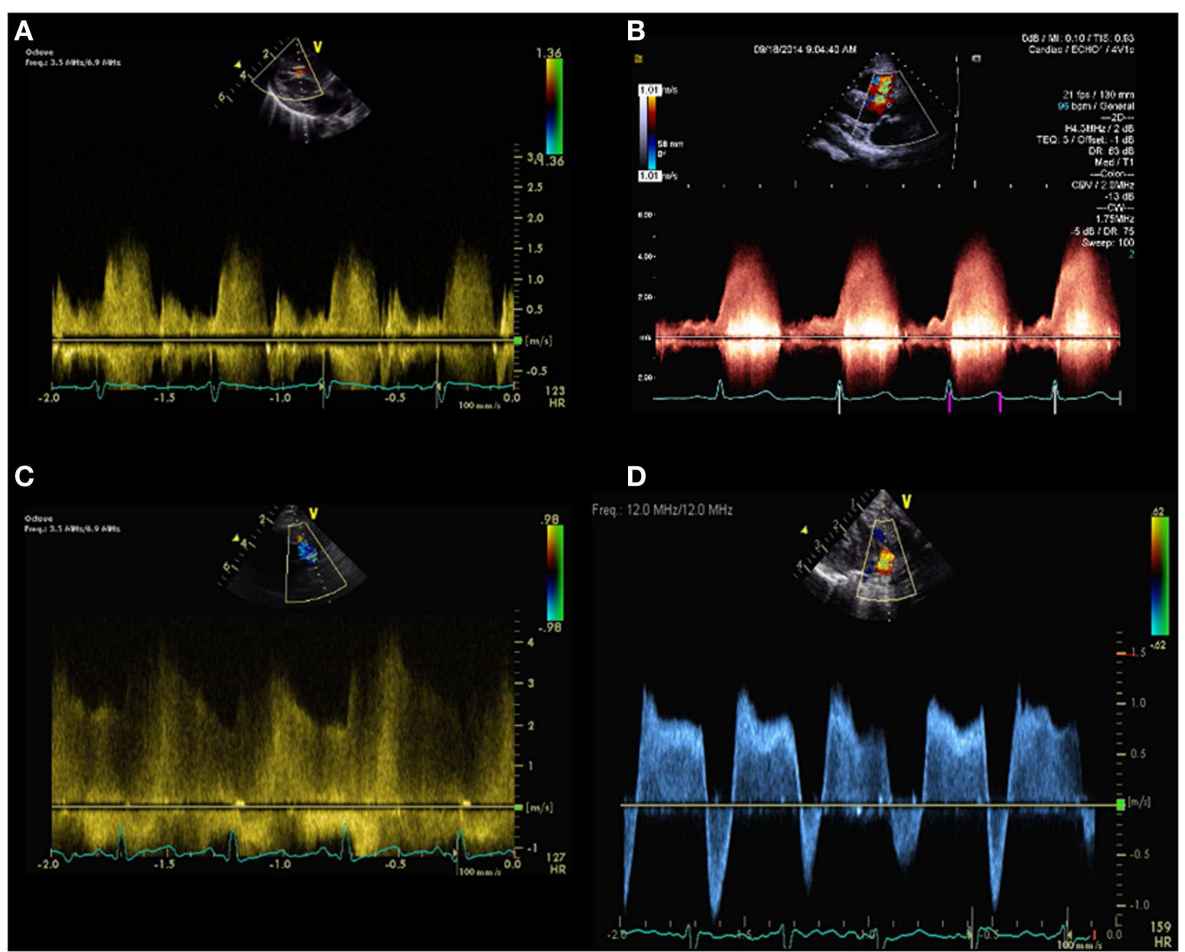

FIGURE 6 | Spectral Doppler pattern across a ventricular septal defect with low velocity left to right shunt (A) indicating pulmonary hypertension and high velocity left to right shunt (B) indicating low pulmonary pressure. Spectral Doppler pattern across patent ductus arteriosus with continuous high velocity left to right shunt (C) indicating lower pulmonary artery pressure compared to aortic pressure and bidirectional shunt (D), indicating pulmonary hypertension. pressures (31). Nevertheless, TR is still used clinically and serially to evaluate children with $\mathrm{PH}$.

Estimation of SPAP can also be made in the presence of ventricular septal defect (VSD). This can only be done if there is no RV or LV outflow tract obstruction. This method has been shown to correlate well with invasive measurements obtained by cardiac catheterization $(32,33)$. The equation is below:

$$
\begin{aligned}
\mathrm{SPAP}= & \text { Systolic blood pressure }(\mathrm{SBP})-4 V \text { (VSD) } \max ^{2} \\
& (\text { for left to right shunts }) \\
\mathrm{SPAP}= & \mathrm{SBP}+4 V \text { (VSD) } \max ^{2} \text { (for right to left shunts) }
\end{aligned}
$$

The maximal velocity across the ventricular septal defect is $V$ (VSD)max. Flow direction and velocity across the VSD may help in the diagnosis of PH. Right to left shunt across the VSD and low velocity left to right shunt may suggest the presence of elevated pulmonary pressure (Figure 6). Parasternal and subcostal long axis views are used to interrogate perimembranous VSDs whereas parasternal and subcostal short axis views are best used to interrogate muscular VSDs.

Lastly, SPAP can be estimated in patients with patent ductus arteriosus (PDA) in the following equation:

$$
\begin{aligned}
& \mathrm{SPAP}=\mathrm{SBP}-4 V(\mathrm{PDA}) \max ^{2} \text { (for left to right shunts) } \\
& \mathrm{SPAP}=\mathrm{SBP}+4 V(\mathrm{PDA}) \max ^{2} \text { (for right to left shunts) }
\end{aligned}
$$

The maximal velocity across the PDA is denoted as $V$ (PDA) max. This method has been validated by invasive measurements in cardiac catheterization (34). The flow and velocity across the PDA are dependent on the pressure between the aorta and the main pulmonary artery. Right to left shunting across the PDA indicates SPAP higher than the aortic pressure (Figure 6). Left to right shunting across the PDA indicates lower SPAP compared to the aortic pressure. Bidirectional shunting across the PDA is a common finding in newborns until the pulmonary vascular resistance (PVR) has decreased (Figure 6).

\section{DIASTOLIC PULMONARY ARTERY PRESSURE}

The diastolic pulmonary artery pressure (DPAP) can be estimated from the velocity of the end-diastolic pulmonary regurgitant velocity using the modified Bernoulli equation (Figure 7):

$$
\begin{aligned}
\text { DPAP }= & 4 V(\text { end-diastolic pulmonary regurgitation velocity })^{2} \\
& + \text { RA pressure }
\end{aligned}
$$

\section{MEAN PULMONARY ARTERY PRESSURE}

The mean pulmonary artery pressure (mPAP) can be estimated from the following equation (Figure 7):

$$
\begin{aligned}
\mathrm{mPAP}= & 4 V(\text { early peak pulmonary regurgitation velocity })^{2} \\
& + \text { RA pressure }
\end{aligned}
$$




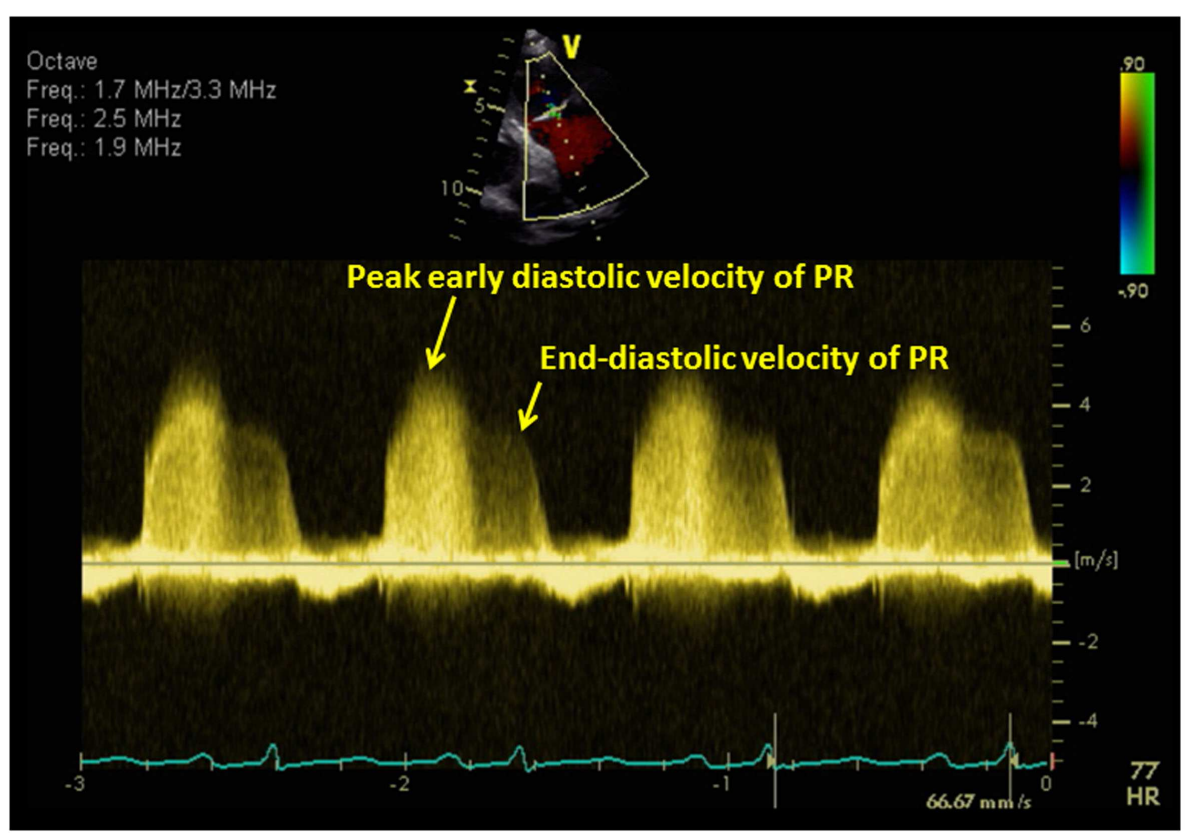

FIGURE 7 |The diastolic pulmonary artery pressure (DPAP) can be estimated from the velocity of the end-diastolic pulmonary regurgitant velocity using the modified Bernoulli equation. The mean pulmonary artery pressure (mPAP) can be estimated from the following equation: $\mathrm{mPAP}=4 \mathrm{~V}$ (early peak pulmonary regurgitation velocity $)^{2}+\mathrm{RA}$ pressure.
This equation has been shown to correlate well with invasive measurements in adults and children $(35,36)$. Another method to estimate mPAP is by using pulmonary acceleration time (AT) measured by pulsed-wave Doppler of the pulmonary artery in systole, where $\mathrm{mPAP}=79-(0.45 \times \mathrm{AT})$ and in patients with AT $<120 \mathrm{~ms}$, the formula for $\mathrm{mPAP}=90-(0.62 \times \mathrm{AT})$ performed better $(37)$. Recently, a newer method to evaluating mPAP is by adding the mean RA pressure to the velocity-time integral of the TR jet. This method has been validated by invasive measurements in adults where the mean difference between mPAP calculated using this method was closer to the right heart catheterization mPAP (38, 39). Some of the equations used to estimate mPAP do not add the mean RA pressure.

\section{PULMONARY VASCULAR RESISTANCE}

Pulmonary vascular resistance is calculated from cardiac catheterization as pressure gradient across the pulmonary bed divided by the pulmonary blood flow. PVR is important in the evaluation of $\mathrm{PH}$ and can be estimated using the following equation:

$$
\mathrm{PVR}=[V(\mathrm{TR}) \max / \mathrm{VTI}(\mathrm{RVOT}) \times 10]+0.16
$$

The VTI(RVOT) denotes the velocity time integral of RVOT that can be obtained by spectral Doppler in the parasternal short axis view. In adults, this echocardiographic derived PVR has been validated with cardiac catheterization (40). In another adult study that included children, PVR can be estimated using a simple ratio of peak TR velocity to the VTI(RVOT) and value of $>38$ provided a specificity of $100 \%$ for a PVR of $>8$ Wood units (WU) (41). However, this relationship is not reliable in patients with very high PVR as determined by invasive hemodynamic measurements (42). In children with congenital heart disease, the ratio of isovolumic time (IVRT) to RV ejection time (ET) has been shown to correlated with PVR, with IVRT/ET $<0.3$ being $97 \%$ specific for a PVR $<3 \mathrm{WU}$ and a IVRT/ET ratio $>0.4$ highly predictive of PVR $>$ 5WU (43). However, other studies did not find a correlation between the ratio of IVRT/ET and PVR. Recently, Panda et al. used TR velocity over VTI(RVOT) ratio (TRV/VTIRVOT) to correlate with invasive measurements of PVR in children with $\mathrm{PH}$ in congenital heart disease (44). The TRV/VTIRVOT ratio correlated well with PVR measured at catheterization. They found that for PVR of $6 \mathrm{WU}$, a TRV/VTIRVOT value of 0.14 provided a sensitivity of $96.67 \%$ and a specificity of $92.86 \%$ and for PVR of $8 \mathrm{WU}$ a TRV/VTIRVOT value of 0.17 provided a sensitivity of $79.17 \%$ and a specificity of $95 \%$ (44). Although echocardiogram can estimate PVR, cardiac catheterization remains the gold standard in diagnosing PVR.

\section{OTHER DOPPLER ECHOCARDIOGRAPHY IN PULMONARY HYPERTENSION}

With rising pulmonary artery pressure, the RV outflow spectral Doppler pattern changes from a smooth round shape to a triangular shape (45). RV AT is also decreased in patients with $\mathrm{PH}$. The ratio of $\mathrm{AT} / \mathrm{ET}<0.3$ is suggestive of $\mathrm{PH}$ but cannot reliably determine the severity of $\mathrm{PH}$. Alkon et al. used a simple measure of systolic to diastolic time $(S / D)$ ratio (Figure 5) from the TR jet to evaluate pediatric $\mathrm{PH}$ patients and found that as the RV function worsens, the systolic portion of the cardiac cycle lengthens leading to an increased $S / D$ ratio (46). $S / D$ ratio was found to be higher in pediatric $\mathrm{PH}$ patients compared to controls and is 
associated with worse hemodynamics by cardiac catheterization, shorter 6 min walk test, and worse clinical outcomes independent of PVR or pressures (46).

\section{RIGHT VENTRICULAR SYSTOLIC FUNCTION}

The RV function has been shown to be an important prognostic determinant of $\mathrm{PH}$. The assessment of RV function is more
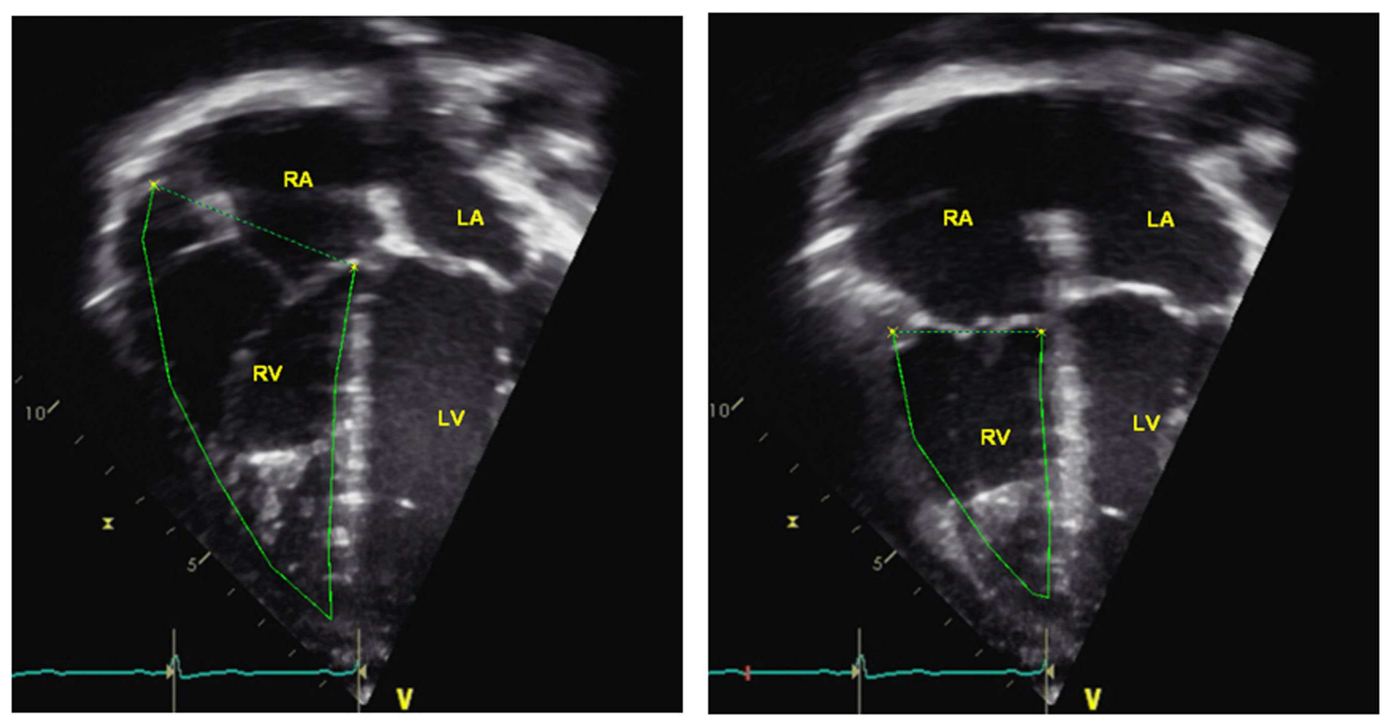

FIGURE 8 | Right ventricular fractional area change $=$ (end-diastolic area-end-systolic area)/end-diastolic area $\times 100 . R A=r i g h t$ atria, $R V=r i g h t$ ventricle, $L A=$ left atria, $L V=$ left ventricle.

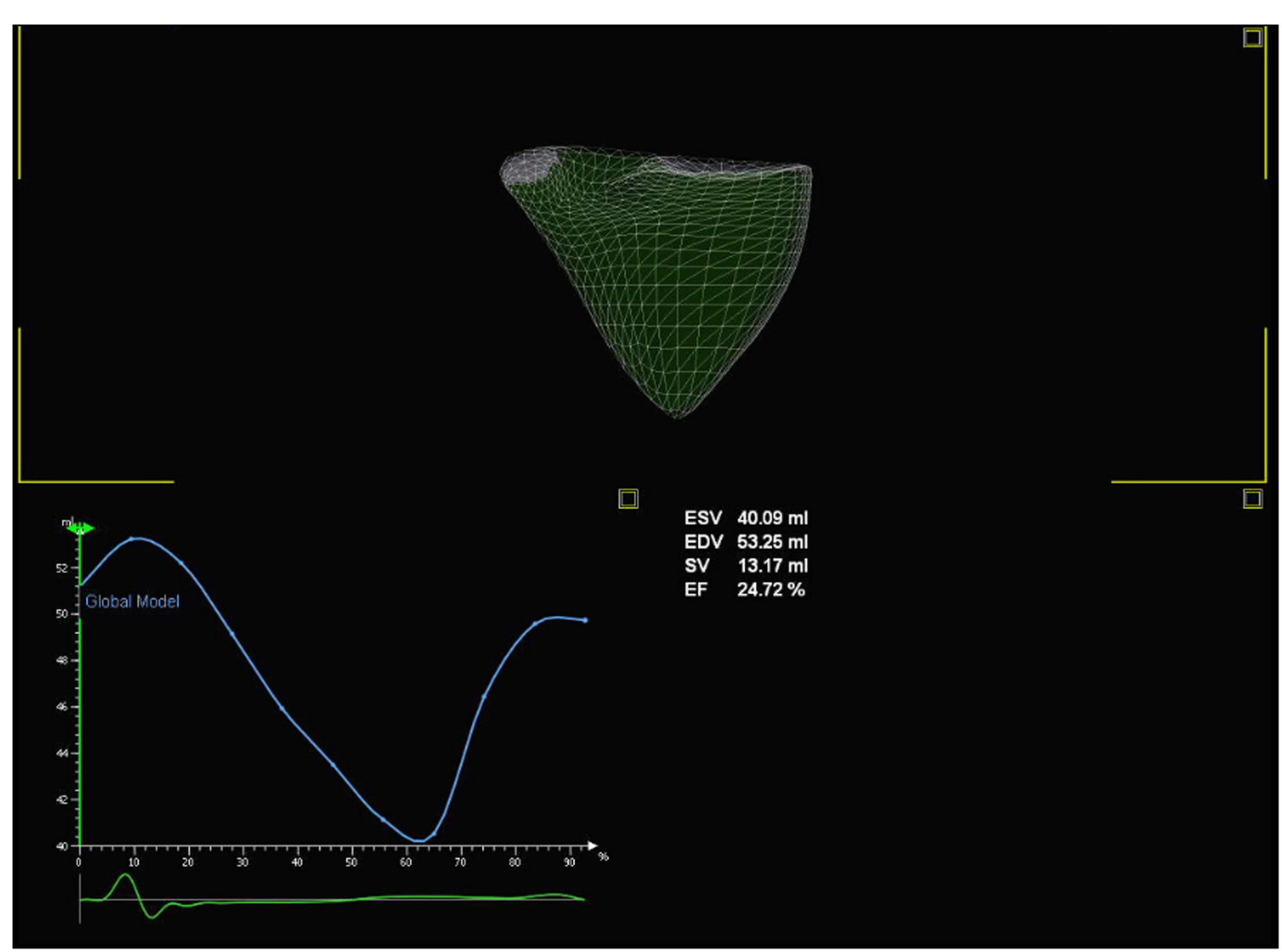

FIGURE 9 |Three-dimensional echocardiography evaluation of the right heart volume and ejection fraction 


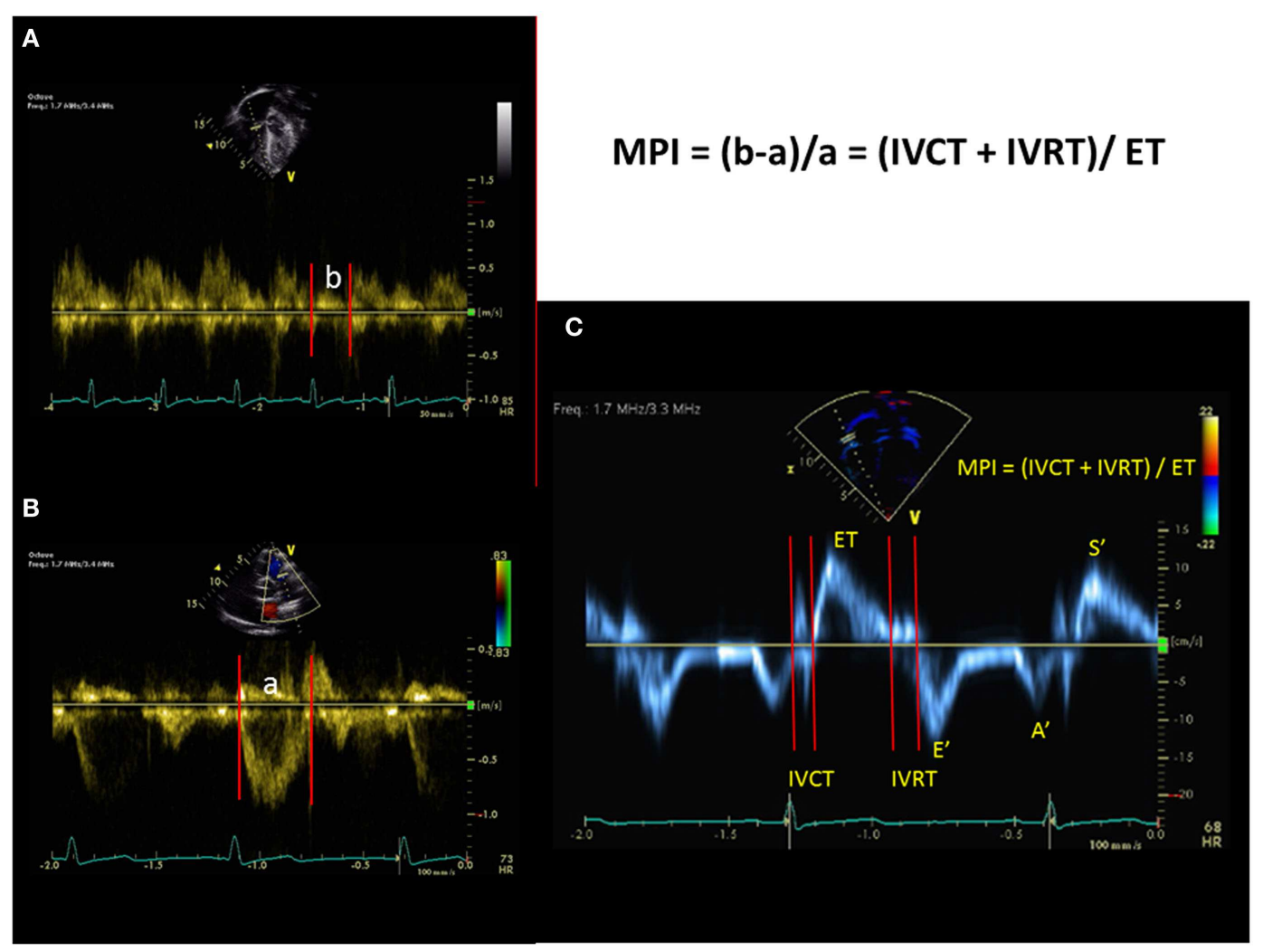

FIGURE 10 |The myocardial performance index (MPI) can be obtained from the spectral Doppler of tricuspid inflow and pulmonary outflow velocities [top left and bottom left, $(A, B)$ ] or can be obtained from tissue Doppler imaging (C) at the lateral annulus of the tricuspid valve. IVCT = isovolumic contraction time, IVRT = isovolumic relation time, and $E T=$ ejection time. Tissue Doppler imaging of the tricuspid valve. $S=$ systolic velocity, $E^{\prime}=$ early diastolic velocity, $A^{\prime}=$ late diastolic velocity. difficult because of its complex geometry and visual assessment of RV function is frequently used (47). The RV is composed of the smooth muscular inflow, the outflow region, and the trabecular apical region. The RV has inner longitudinal fibers that result in base to apex contraction and superficial circumferential muscle fibers responsible for its inward bellow movement (48). The evaluation of RV systolic function can be divided into global and regional systolic function.

\section{GLOBAL ASSESSMENT OF RIGHT VENTRICULAR FUNCTION $R V$ fractional area change}

The RV fractional area change (FAC) is a measure of RV systolic function and can be calculated by the following equation:

$$
\begin{aligned}
\text { RVFAC }= & (\text { end-diastolic area-end-systolic area }) / \\
& \text { end-diastolic area } \times 100
\end{aligned}
$$

The RV FAC can be obtained by tracing the RV endocardium both in systole and diastole from the tricuspid valve annulus, along the right free wall to the apex, and then back to the tricuspid valve annulus, along the IVS (Figure 8). RV FAC has been shown to correlate with RV ejection fraction (EF) by magnetic resonance imaging (MRI) (49). In adults, the lower reference value for normal RV FAC is $35 \%$. In pediatric patients with idiopathic PAH, RV FAC was found to be significantly worse in patient who did not survive at follow-up when compared to patients who survived (6).

\section{Three-dimensional volume and EF estimation}

By eliminating the need for geometric assumptions, threedimensional (3D) echocardiography provides more accurate and reproducible measurements of $\mathrm{RV}$ volume and $\mathrm{EF}$ in adults with PH (Figure 9) (50). Disk summation and apical rotational methods for RV volume and EF calculation are the most commonly used methods in 3D echocardiography. Both methods have been shown to correlate well with MRI volume and EF in children (51-54) and in adults (55-61). The lower reference limit for RV $\mathrm{EF}$ is $44 \%$ from disk summation method in adult patients. In a recent study by Kong et al. regional and global RV systolic dysfunction in adult $\mathrm{PH}$ patients measured by $3 \mathrm{D}$ echocardiography were inversely related to the PASP and PVR (62). Measurements of volumes and EF become difficult in patients with arrhythmia and breath holding in small children maybe a limiting factor; however, with the advent of newer software using semi-automated quantification of RV volume and EF, breath holding is no longer required. $\mathrm{RV}$ volume and EF from 3D echocardiography can be accurately 


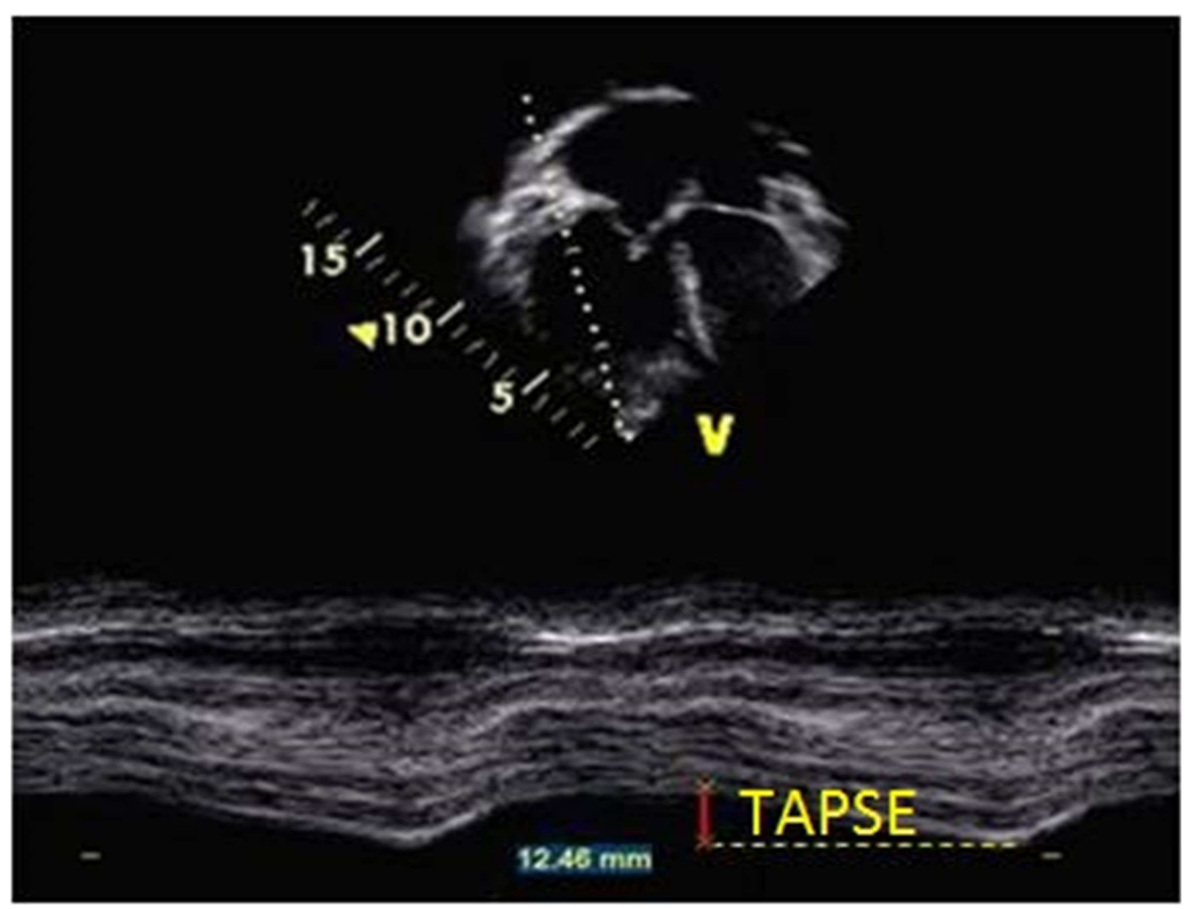

FIGURE 11 | Measurement of tricuspid annular plane systolic excursion (TAPSE) from M-mode in the apical four-chamber view at the level of the tricuspid annulus in a patient with pulmonary hypertension.

measured using real-time 3D algorithms and need further studies in children with $\mathrm{PH}$.

\section{MYOCARDIAL PERFORMANCE INDEX}

The myocardial performance index (MPI) is a non-invasive measurement of global ventricular function (systolic and diastolic) independent of geometric assumptions (63). It can be applied to the RV and the LV. It is defined as the ratio of isovolumic time divided by the ET.

$$
\mathrm{MPI}=(\text { isovolumic contraction time }(\mathrm{IVCT})+\mathrm{IVRT}) / \mathrm{ET}
$$

The MPI is easily obtained from either the spectral Doppler or from tissue Doppler imaging (TDI) (Figure 10). RV MPI is difficult to obtain in one single heart beat or similar heart beat because it is difficult to image the tricuspid valve and pulmonary valve in the same spectral Doppler signal. This results in errors in the calculation of the RV MPI. In TDI, the RV MPI is more easily measured from a single heart beat by sampling at the tricuspid annulus. RV MPI using the spectral Doppler has been studied in pediatric patients with $\mathrm{PH}$. It is increased in $\mathrm{PH}$ patients compared to controls and RV MPI correlated well with both MPAP at cardiac catheterization and response to therapy. (64) Another study in infants with $\mathrm{PH}$ from congenital diaphragmatic hernia has shown that RV MPI is elevated compared to controls, but did not correlate well with SPAP (65). RV MPI may be a useful tool to follow $\mathrm{PH}$ patients serially but it may be unreliable if there is significant TR with an elevated RA pressure because the IVRT will shorten and result in an inappropriately lower value of MPI. RV
MPI will not work if patients have irregular heart rates. There are currently no studies in children using TDI method of RV MPI to evaluate pediatric $\mathrm{PH}$ and further studies are needed in this area.

\section{REGIONAL ASSESSMENT OF RIGHT VENTRICULAR FUNCTION Tricuspid annular plane systolic excursion}

The longitudinal fibers are the major contributor to RV systolic function. Tricuspid annular plane systolic excursion (TAPSE) is a method to measure the distance of systolic excursion of the RV annular segment along its longitudinal plane from the apical four chamber view in millimeters from end-diastole to end-systole. The greater the descent of the basal annulus in systole, the better $\mathrm{RV}$ systolic function is. TAPSE is usually acquired by placing the M-mode cursor through the lateral tricuspid annulus and measuring the amount of longitudinal motion of the annulus in peak systole (Figure 11). TAPSE $<18 \mathrm{~mm}$ has been demonstrated in adult patients with $\mathrm{PH}$ to be associated with greater RV systolic dysfunction and lower survival rate (66). There is also a strong correlation between TAPSE and reduced RV FAC regardless of pulmonary artery pressures in adults (67). Normal values for TAPSE in children have been published and $z$-scores established (68). Children with idiopathic PAH who had TAPSE $z$-score $<-4.3$ were associated with increased risk of transplant or death (6). The advantage of using TAPSE is that it is a simple and reproducible measure but it is important to note that TAPSE is angle and load dependent. TAPSE is also one-dimensional and does not take into the account the three-dimensional structure of the RV. TAPSE does not evaluate apical systolic dysfunction in patients with $\mathrm{PH}$. 


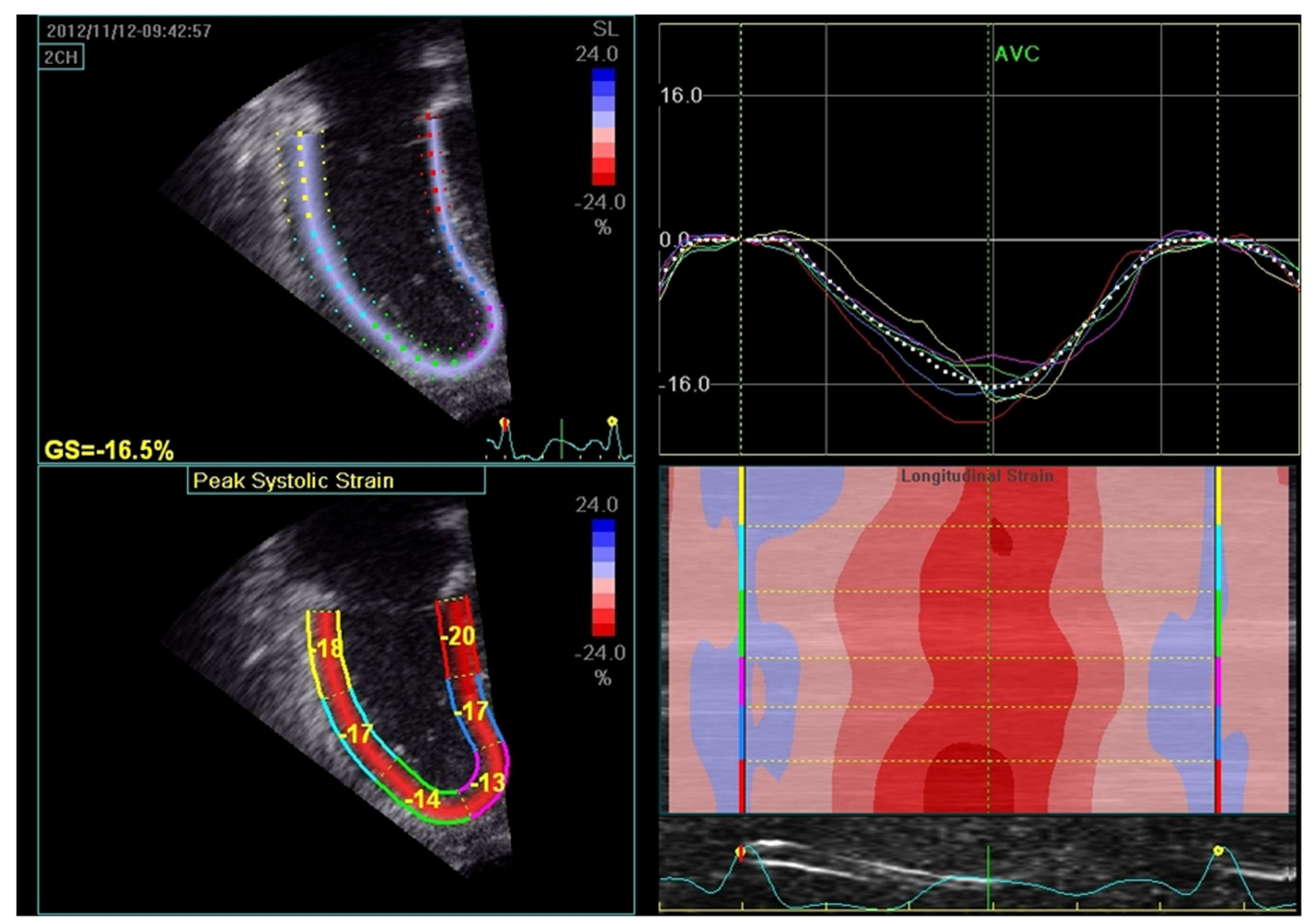

FIGURE 12 |The left upper panel shows 2D strain (speckle tracking) of right ventricle in pulmonary hypertension patient. The right upper panel represents the strain curves sampled in each of the analyzed myocardial segments and decreased global longitudinal strain (GS $=-16.5 \%$ ). The lower left panel measures the peak systolic strain in each of the myocardial segments. The lower right panel depicts the longitudinal strain according to the color map of M-mode; red segments indicate higher contractility.

\section{Tissue Doppler imaging}

Tissue Doppler imaging measures the myocardial velocities in the apical four chamber view with the pulse-wave Doppler sample volume placed at the level of RV lateral tricuspid, basal IVS, and LV lateral mitral annuli (Figure 10). Myocardial systolic wave $\left(S^{\prime}\right)$ measures the systolic longitudinal function of the RV or the LV and two diastolic waves: early diastolic $\left(E^{\prime}\right)$ and late diastolic $\left(A^{\prime}\right)$ denote the diastolic function of the ventricles. Pulse-wave TDI measures the peak myocardial velocities and color TDI measures the mean velocities, which is lower than the pulse-wave TDI measurements by $20 \%$. Acquisition of the TDI velocities must be as parallel as possible to avoid underestimation of the velocities. In adults with idiopathic $\mathrm{PH}$, tricuspid and septal peak systolic $\left(S^{\prime}\right)$ velocities relate to the RV dysfunction and cut-off values have been described to predict RV systolic dysfunction (69). RV $S^{\prime}$ at the tricuspid valve has also been shown to have an inverse relationship with cardiac catheterization MPAP and PVR in adults. (70) RV $S^{\prime}$ at the tricuspid valve has been shown to correlate with RV FAC and TAPSE (67). The lower limit value of RV $S^{\prime}$ at the tricuspid valve in adults is $<10 \mathrm{~cm} / \mathrm{s}$ (3). A strong correlation has been shown between RV $S^{\prime}$ at the tricuspid valve and $\mathrm{RV}$ EF with a $\mathrm{RV} S^{\prime}<10 \mathrm{~cm} / \mathrm{s}$ predicting $\mathrm{RV} \mathrm{EF}<40 \%$ (71, 72). In infants with $\mathrm{PH}, \mathrm{RV} S^{\prime}$ at the tricuspid valve is lower compared to controls (73). RV $S^{\prime}$ by pulsed Doppler is a simple, reproducible measure of basal RV free wall function and should be used in the assessment of RV regional systolic function.

\section{Strain and strain rate}

Strain measures the percentage change in myocardial deformation whereas its time derivative, strain rate, defines the rate of deformation of myocardium over time. Strain is load-independent global measure of ventricular systolic function and correlates closely with myocardial contractility (Figure 12). Strain can measure regional and global systolic function. Using speckle tracking, longitudinal strain is displayed as a negative wave. For the $\mathrm{RV}$, longitudinal and radial strain and strain rate are typically assessed. Optimal quality images with frame rates between 60 and 90 frames/s during image acquisition are necessary prerequisites for reproducibility and reliability of the data. RV free wall strain imaging has been applied to adult patients with $\mathrm{PH}$ and has been shown to correlate with invasive pulmonary hemodynamics (74). Recently, Fine et al. demonstrated that RV longitudinal strain is a powerful tool to predict clinical outcome in adults with $\mathrm{PH}$ (75). Smith et al. demonstrated that 3D area strain, radial strain, longitudinal strain, and circumferential strain were lower in adult $\mathrm{PH}$ patients compared to controls and reduced area strain, longitudinal strain, circumferential strain, and EF were all determinants of mortality in adults with PH (76). The disadvantages of strain are that there are many different vendors with strain software and no 
standard methods of measuring strain. Some are deriving strain and strain rate from velocity vector imaging (VVI) and others derive it from speckle tracking. Normal values for the RV and LV strain have been published in children (77). Normal ranges of RV systolic and diastolic strain measures in children using speckle tracking have been published in a meta-analysis (78). Evaluation of $2 \mathrm{D} \mathrm{RV}$ strain in children with $\mathrm{PH}$ is promising but requires further research. 3D strain has not been investigated in children and will require further research.

\section{RIGHT VENTRICULAR DIASTOLIC FUNCTION}

Pulmonary hypertension can result in RV diastolic dysfunction, which affects outcome in these patients. In the apical four chamber view, a pulsed Doppler beam should be aligned as parallel as possible to RV inflow. The sample volume should be placed at the tip of the tricuspid leaflets (79). Tricuspid inflow can be achieved with high reproducibility (80). The presence of moderate to severe TR can confound measurements of the tricuspid inflow velocities ( $E$ and $A$ ) and are excluded from most studies. The evaluation of RV diastolic function includes tricuspid inflow velocities $(E, A, E / A)$, TDI of the tricuspid annulus $\left(E^{\prime}, A^{\prime}\right.$, and $\left.E^{\prime} / A^{\prime}\right)$, deceleration time, and IVRT. The tricuspid $E / E^{\prime}$ ratio, RA area, and diastolic strain rate have shown promise in the evaluation of RV diastolic function. In adult studies with chronic heart failure and $\mathrm{PH}$, the presence of $\mathrm{RV}$ diastolic dysfunction is associated with worse functional class and is an independent predictor of mortality (81). In infants with $\mathrm{PH}$, diastolic $E^{\prime}$ velocities have been shown to be lower than controls (73). In pediatric patients with bronchopulmonary dysplasia, increasing tricuspid $E / E^{\prime}$ has been shown to correlate with clinical severity of the disease (82). In children with idiopathic PAH, tricuspid valve $E^{\prime}$ correlated with $\mathrm{MPAP}$ and RV end-diastolic pressure (83). In this study, the tricuspid valve $E^{\prime}$ was lower in worse functional class and the cumulative event-free survival rate was significantly lower when tricuspid valve $E^{\prime}$ was $<8 \mathrm{~cm} / \mathrm{s}$ (83). In a recent study, echocardiographic diastolic parameters of $\mathrm{RV}$ in children with PAH correlated with invasive measures of cardiac catheterization and tricuspid deceleration time with global early diastolic strain rate were independent predictors of tau (84).

\section{LEFT VENTRICULAR DIASTOLIC AND SYSTOLIC FUNCTION}

In $\mathrm{PH}$ patients, the late diastolic filling pattern through the mitral valve will reverse with $E<A, E / A<1$, and a short $E$ deceleration time have been observed in adults (85). The pulmonary venous Doppler can be abnormal in patients with LV diastolic dysfunction. In patient with $\mathrm{PH}$ from left sided heart disease, the evaluation of mitral valve and pulmonary veins remains important in determining the cause of PH. Evaluation of the LV systolic function can be measured by EF from bi-plane Simpson's formula $(86,87)$.

\section{CONCLUSION}

Echocardiography is a valuable non-invasive tool in screening, diagnosing, and assessing pediatric $\mathrm{PH}$. Echocardiography provides indirect measurements of pulmonary artery pressures, which can help in the initial assessment and follow-up of these patients. Echocardiographic assessment of RV function is important in this population and can be used as a chronic surveillance of these patients. Advancement in technology has allowed new techniques in evaluating RV function (3D echocardiography, strain, and strain rate) using echocardiography but more data are needed in the pediatric population in the reproducibility of these new techniques.

\section{ACKNOWLEDGEMENTS}

This manuscript was supported by the Jayden de Luca and the Frederick and Margaret Weyerhauser Foundations.

\section{REFERENCES}

1. Ivy DD, Abman SH, Barst RJ, Berger RM, Bonnet D, Fleming TR, et al. Pediatric pulmonary hypertension. J Am Coll Cardiol (2013) 62(25 Suppl):D117-26. doi:10.1016/j.jacc.2013.10.028

2. Gaynor SL, Maniar HS, Prasad SM, Steendijk P, Moon MR. Reservoir and conduit function of right atrium: impact on right ventricular filling and cardiac output. Am J Physiol Heart Circ Physiol (2005) 288(5):H2140-5. doi:10.1152/ ajpheart.00566.2004

3. Rudski LG, Lai WW, Afilalo J, Hua L, Handschumacher MD, Chandrasekaran $\mathrm{K}$, et al. Guidelines for the echocardiographic assessment of the right heart in adults: a report from the American Society of Echocardiography endorsed by the European Association of Echocardiography, a registered branch of the European Society of Cardiology, and the Canadian Society of Echocardiography. J Am Soc Echocardiogr (2010) 23(7):685-713; quiz 86-8. doi:10.1016/j.echo.2010.05.010

4. Tonelli AR, Conci D, Tamarappoo BK, Newman J, Dweik RA. Prognostic value of echocardiographic changes in patients with pulmonary arterial hypertension receiving parenteral prostacyclin therapy. J Am Soc Echocardiogr (2014) 27(7): 733-741.e2. doi:10.1016/j.echo.2014.03.012

5. Raymond RJ, Hinderliter AL, Willis PW, Ralph D, Caldwell EJ, Williams W, et al. Echocardiographic predictors of adverse outcomes in primary pulmonary hypertension. J Am Coll Cardiol (2002) 39(7):1214-9. doi:10.1016/S07351097(02)01744-8

6. Kassem E, Humpl T, Friedberg MK. Prognostic significance of 2-dimensional, M-mode, and Doppler echo indices of right ventricular function in children with pulmonary arterial hypertension. Am Heart J (2013) 165(6):1024-31. doi:10.1016/j.ahj.2013.02.027

7. Moreno FL, Hagan AD, Holmen JR, Pryor TA, Strickland RD, Castle CH. Evaluation of size and dynamics of the inferior vena cava as an index of right-sided cardiac function. Am J Cardiol (1984) 53(4):579-85. doi:10.1016/0002-9149(84) 90034- 1

8. Brennan JM, Blair JE, Goonewardena S, Ronan A, Shah D, Vasaiwala S, et al. Reappraisal of the use of inferior vena cava for estimating right atrial pressure. J Am Soc Echocardiogr (2007) 20(7):857-61. doi:10.1016/j.echo.2007.01.005

9. Kircher BJ, Himelman RB, Schiller NB. Noninvasive estimation of right atrial pressure from the inspiratory collapse of the inferior vena cava. Am J Cardiol (1990) 66(4):493-6. doi:10.1016/0002-9149(90)90711-9

10. Ommen SR, Nishimura RA, Hurrell DG, Klarich KW. Assessment of right atrial pressure with 2-dimensional and Doppler echocardiography: a simultaneous catheterization and echocardiographic study. Mayo Clin Proc (2000) 75(1):24-9. doi:10.4065/75.1.24

11. Beigel R, Cercek B, Luo H, Siegel RJ. Noninvasive evaluation of right atrial pressure. J Am Soc Echocardiogr (2013) 26(9):1033-42. doi:10.1016/j.echo.2013.06. 004

12. Lang RM, Bierig M, Devereux RB, Flachskampf FA, Foster E, Pellikka PA, et al. Recommendations for chamber quantification. Eur J Echocardiogr (2006) 7(2):79-108. doi:10.1016/j.euje.2005.12.014

13. Burgess MI, Mogulkoc N, Bright-Thomas RJ, Bishop P, Egan JJ, Ray SG. Comparison of echocardiographic markers of right ventricular function in determining prognosis in chronic pulmonary disease. J Am Soc Echocardiogr (2002) 15(6):633-9. doi:10.1067/mje.2002.118526

14. Milan A, Magnino C, Veglio F. Echocardiographic indexes for the noninvasive evaluation of pulmonary hemodynamics. J Am Soc Echocardiogr (2010) 23(3):225-39; quiz 332-4. doi:10.1016/j.echo.2010.01.003

15. Ryan T, Petrovic O, Dillon JC, Feigenbaum H, Conley MJ, Armstrong WF. An echocardiographic index for separation of right ventricular volume and pressure overload. J Am Coll Cardiol (1985) 5(4):918-27. doi:10.1016/S0735-1097(85) 80433-2

16. Lopez-Candales A, Rajagopalan N, Kochar M, Gulyasy B, Edelman K. Systolic eccentricity index identifies right ventricular dysfunction in pulmonary hypertension. Int J Cardiol (2008) 129(3):424-6. doi:10.1016/j.ijcard.2007.06.057 
17. Galie N, Hinderliter AL, Torbicki A, Fourme T, Simonneau G, Pulido T, et al. Effects of the oral endothelin-receptor antagonist bosentan on echocardiographic and Doppler measures in patients with pulmonary arterial hypertension. J Am Coll Cardiol (2003) 41(8):1380-6. doi:10.1016/S0735-1097(03)00121-9

18. King ME, Braun H, Goldblatt A, Liberthson R, Weyman AE. Interventricular septal configuration as a predictor of right ventricular systolic hypertension in children: a cross-sectional echocardiographic study. Circulation (1983) 68(1):68-75. doi:10.1161/01.CIR.68.1.68

19. Jone PN, Hinzman J, Wagner BD, Ivy DD, Younoszai A. Right ventricular to left ventricular diameter ratio at end-systole in evaluating outcomes in children with pulmonary hypertension. J Am Soc Echocardiogr (2014) 27(2):172-8. doi:10.1016/j.echo.2013.10.014

20. Mori S, Nakatani S, Kanzaki H, Yamagata K, Take Y, Matsuura Y, et al. Patterns of the interventricular septal motion can predict conditions of patients with pulmonary hypertension. J Am Soc Echocardiogr (2008) 21(4):386-93. doi:10.1016/j.echo.2007.05.037

21. Puwanant S, Park M, Popovic ZB, Tang WH, Farha S, George D, et al. Ventricular geometry, strain, and rotational mechanics in pulmonary hypertension. Circulation (2010) 121(2):259-66. doi:10.1161/CIRCULATIONAHA.108.844340

22. Sandoval J, Rothman A, Pulido T. Atrial septostomy for pulmonary hypertension. Clin Chest Med (2001) 22(3):547-60. doi:10.1016/S0272-5231(05)70291-4

23. Sandoval J, Gaspar J, Pena H, Santos LE, Cordova J, del Valle K, et al. Effect of atrial septostomy on the survival of patients with severe pulmonary arterial hypertension. Eur Respir J (2011) 38(6):1343-8. doi:10.1183/09031936. 00072210

24. Fischer A, Misumi S, Curran-Everett D, Meehan RT, Ulrich SK, Swigris JJ, et al. Pericardial abnormalities predict the presence of echocardiographically defined pulmonary arterial hypertension in systemic sclerosis-related interstitial lung disease. Chest (2007) 131(4):988-92. doi:10.1378/chest.06-2317

25. Bossone E, Rubenfire M, Bach DS, Ricciardi M, Armstrong WF. Range of tricuspid regurgitation velocity at rest and during exercise in normal adult men: implications for the diagnosis of pulmonary hypertension. J Am Coll Cardiol (1999) 33(6):1662-6. doi:10.1016/S0735-1097(99)00055-8

26. McQuillan BM, Picard MH, Leavitt M, Weyman AE. Clinical correlates and reference intervals for pulmonary artery systolic pressure among echocardiographically normal subjects. Circulation (2001) 104(23):2797-802. doi:10.1161/ hc4801.100076

27. Hatle L, Angelsen BA, Tromsdal A. Non-invasive estimation of pulmonary artery systolic pressure with Doppler ultrasound. Br Heart J (1981) 45(2):157-65. doi:10.1136/hrt.45.2.157

28. Yock PG, Popp RL. Noninvasive estimation of right ventricular systolic pressure by Doppler ultrasound in patients with tricuspid regurgitation. Circulation (1984) 70(4):657-62. doi:10.1161/01.CIR.70.4.657

29. Berger M, Haimowitz A, Van Tosh A, Berdoff RL, Goldberg E. Quantitative assessment of pulmonary hypertension in patients with tricuspid regurgitation using continuous wave Doppler ultrasound. J Am Coll Cardiol (1985) 6(2):359-65. doi:10.1016/S0735-1097(85)80172-8

30. Mourani PM, Sontag MK, Younoszai A, Ivy DD, Abman SH. Clinical utility of echocardiography for the diagnosis and management of pulmonary vascular disease in young children with chronic lung disease. Pediatrics (2008) 121(2):317-25. doi:10.1542/peds.2007-1583

31. Groh GK, Levy PT, Holland MR, Murphy JJ, Sekarski TJ, Myers CL, et al. Doppler echocardiography inaccurately estimates right ventricular pressure in children with elevated right heart pressure. J Am Soc Echocardiogr (2014) 27(2):163-71. doi:10.1016/j.echo.2013.09.016

32. Ge Z, Zhang Y, Kang W, Fan D, An F. Noninvasive evaluation of interventricular pressure gradient across ventricular septal defect: a simultaneous study of Doppler echocardiography and cardiac catheterization. Am Heart J (1992) 124(1):176-82. doi:10.1016/0002-8703(92)90938-R

33. Marx GR, Allen HD, Goldberg SJ. Doppler echocardiographic estimation of systolic pulmonary artery pressure in pediatric patients with interventricular communications. J Am Coll Cardiol (1985) 6(5):1132-7. doi:10.1016/S07351097(85)80320-X

34. Ge ZM, Zhang Y, Fan DS, Fan JX, Ji XP, Zhao YX, et al. Reliability and accuracy of measurement of transductal gradient by Doppler ultrasound. Int J Cardiol (1993) 40(1):35-43. doi:10.1016/0167-5273(93)90228-9

35. Masuyama T, Kodama K, Kitabatake A, Sato H, Nanto S, Inoue M. Continuouswave Doppler echocardiographic detection of pulmonary regurgitation and its application to noninvasive estimation of pulmonary artery pressure. Circulation (1986) 74(3):484-92. doi:10.1161/01.CIR.74.3.484

36. Abbas AE, Fortuin FD, Schiller NB, Appleton CP, Moreno CA, Lester SJ. Echocardiographic determination of mean pulmonary artery pressure. Am J Cardiol (2003) 92(11):1373-6. doi:10.1016/j.amjcard.2003.08.037

37. Dabestani A, Mahan G, Gardin JM, Takenaka K, Burn C, Allfie A, et al. Evaluation of pulmonary artery pressure and resistance by pulsed Doppler echocardiography. Am J Cardiol (1987) 59(6):662-8. doi:10.1016/00029149(87)91189-1

38. Aduen JF, Castello R, Lozano MM, Hepler GN, Keller CA, Alvarez F, et al. An alternative echocardiographic method to estimate mean pulmonary artery pressure: diagnostic and clinical implications. J Am Soc Echocardiogr (2009) 22(7):814-9. doi:10.1016/j.echo.2009.04.007

39. Ristow B, Schiller NB. Stepping away from ritual right heart catheterization into the era of noninvasively measured pulmonary artery pressure. J Am Soc Echocardiogr (2009) 22(7):820-2. doi:10.1016/j.echo.2009.05.023

40. Abbas AE, Fortuin FD, Schiller NB, Appleton CP, Moreno CA, Lester SJ. A simple method for noninvasive estimation of pulmonary vascular resistance. J Am Coll Cardiol (2003) 41(6):1021-7. doi:10.1016/S0735-1097(02)02973-X

41. Vlahos AP, Feinstein JA, Schiller NB, Silverman NH. Extension of Dopplerderived echocardiographic measures of pulmonary vascular resistance to patients with moderate or severe pulmonary vascular disease. J Am Soc Echocar$\operatorname{diogr}(2008)$ 21(6):711-4. doi:10.1016/j.echo.2007.10.004

42. Rajagopalan N, Simon MA, Suffoletto MS, Shah H, Edelman K, Mathier MA, et al. Noninvasive estimation of pulmonary vascular resistance in pulmonary hypertension. Echocardiography (2009) 26(5):489-94. doi:10.1111/j.1540-8175. 2008.00837. $\mathrm{x}$

43. Hirschfeld S, Meyer R, Schwartz DC, Kofhagen J, Kaplan S. The echocardiographic assessment of pulmonary artery pressure and pulmonary vascular resistance. Circulation (1975) 52(4):642-50. doi:10.1161/01.CIR.52.4.642

44. Pande A, Sarkar A, Ahmed I, Naveen Chandra G, Patil SK, Kundu CK, et al. Noninvasive estimation of pulmonary vascular resistance in patients of pulmonary hypertension in congenital heart disease with unobstructed pulmonary flow. Ann Pediatr Cardiol (2014) 7(2):92-7. doi:10.4103/0974-2069.132475

45. Kitabatake A, Inoue M, Asao M, Masuyama T, Tanouchi J, Morita T, et al. Noninvasive evaluation of pulmonary hypertension by a pulsed Doppler technique. Circulation (1983) 68(2):302-9. doi:10.1161/01.CIR.68.2.302

46. Alkon J, Humpl T, Manlhiot C, McCrindle BW, Reyes JT, Friedberg MK. Usefulness of the right ventricular systolic to diastolic duration ratio to predict functional capacity and survival in children with pulmonary arterial hypertension. Am J Cardiol (2010) 106(3):430-6. doi:10.1016/j.amjcard.2010.03.048

47. Friedberg MK, Redington AN. Right versus left ventricular failure: differences, similarities, and interactions. Circulation (2014) 129(9):1033-44. doi:10.1161/ CIRCULATIONAHA.113.001375

48. Haddad F, Hunt SA, Rosenthal DN, Murphy DJ. Right ventricular function in cardiovascular disease, part I: anatomy, physiology, aging, and functional assessment of the right ventricle. Circulation (2008) 117(11):1436-48. doi:10.1161/CIRCULATIONAHA.107.653584

49. Anavekar NS, Gerson D, Skali H, Kwong RY, Yucel EK, Solomon SD. Twodimensional assessment of right ventricular function: an echocardiographicMRI correlative study. Echocardiography (2007) 24(5):452-6. doi:10.1111/j. 1540-8175.2007.00424.x

50. Apfel HD, Shen Z, Gopal AS, Vangi V, Solowiejczyk D, Altmann K, et al. Quantitative three dimensional echocardiography in patients with pulmonary hypertension and compressed left ventricles: comparison with cross sectional echocardiography and magnetic resonance imaging. Heart (1996) 76(4):350-4. doi:10.1136/hrt.76.4.350

51. Lu X, Nadvoretskiy V, Bu L, Stolpen A, Ayres N, Pignatelli RH, et al. Accuracy and reproducibility of real-time three-dimensional echocardiography for assessment of right ventricular volumes and ejection fraction in children. J Am Soc Echocardiogr (2008) 21(1):84-9. doi:10.1016/j.echo.2007.05.009

52. Niemann PS, Pinho L, Balbach T, Galuschky C, Blankenhagen M, Silberbach $\mathrm{M}$, et al. Anatomically oriented right ventricular volume measurements with dynamic three-dimensional echocardiography validated by 3 -Tesla magnetic resonance imaging. J Am Coll Cardiol (2007) 50(17):1668-76. doi:10.1016/j. jacc.2007.07.031

53. Papavassiliou DP, Parks WJ, Hopkins KL, Fyfe DA. Three-dimensional echocardiographic measurement of right ventricular volume in children with congenital 
heart disease validated by magnetic resonance imaging. J Am Soc Echocardiogr (1998) 11(8):770-7. doi:10.1016/S0894-7317(98)70051-3

54. Renella P, Marx GR, Zhou J, Gauvreau K, Geva T. Feasibility and reproducibility of three-dimensional echocardiographic assessment of right ventricular size and function in pediatric patients. J Am Soc Echocardiogr (2014) 27(8):903-10. doi:10.1016/j.echo.2014.04.008

55. Vogel M, Gutberlet M, Dittrich S, Hosten N, Lange PE. Comparison of transthoracic three dimensional echocardiography with magnetic resonance imaging in the assessment of right ventricular volume and mass. Heart (1997) 78(2):127-30. doi:10.1136/hrt.78.2.127

56. Leibundgut G, Rohner A, Grize L, Bernheim A, Kessel-Schaefer A, Bremerich J, et al. Dynamic assessment of right ventricular volumes and function by real-time three-dimensional echocardiography: a comparison study with magnetic resonance imaging in 100 adult patients. J Am Soc Echocardiogr (2010) 23(2):116-26. doi:10.1016/j.echo.2009.11.016

57. van der Zwaan HB, Helbing WA, Boersma E, Geleijnse ML, McGhie JS, Soliman OI, et al. Usefulness of real-time three-dimensional echocardiography to identify right ventricular dysfunction in patients with congenital heart disease. Am J Cardiol (2010) 106(6):843-50. doi:10.1016/j.amjcard.2010.05.008

58. van der Zwaan HB, Helbing WA, McGhie JS, Geleijnse ML, Luijnenburg SE, Roos-Hesselink JW, et al. Clinical value of real-time three-dimensional echocardiography for right ventricular quantification in congenital heart disease: validation with cardiac magnetic resonance imaging. J Am Soc Echocardiogr (2010) 23(2):134-40. doi:10.1016/j.echo.2009.12.001

59. Jenkins C, Chan J, Bricknell K, Strudwick M, Marwick TH. Reproducibility of right ventricular volumes and ejection fraction using real-time threedimensional echocardiography: comparison with cardiac MRI. Chest (2007) 131(6):1844-51. doi:10.1378/chest.06-2143

60. Grewal J, Majdalany D, Syed I, Pellikka P, Warnes CA. Three-dimensional echocardiographic assessment of right ventricular volume and function in adult patients with congenital heart disease: comparison with magnetic resonance imaging. J Am Soc Echocardiogr (2010) 23(2):127-33. doi:10.1016/j.echo.2009. 11.002

61. Tamborini G, Marsan NA, Gripari P, Maffessanti F, Brusoni D, Muratori M, et al. Reference values for right ventricular volumes and ejection fraction with realtime three-dimensional echocardiography: evaluation in a large series of normal subjects. J Am Soc Echocardiogr (2010) 23(2):109-15. doi:10.1016/j.echo.2009. 11.026

62. Kong D, Shu X, Dong L, Pan C, Cheng L, Yao H, et al. Right ventricular regional systolic function and dyssynchrony in patients with pulmonary hypertension evaluated by three-dimensional echocardiography. J Am Soc Echocardiogr (2013) 26(6):649-56. doi:10.1016/j.echo.2013.03.007

63. Tei C, Dujardin KS, Hodge DO, Bailey KR, McGoon MD, Tajik AJ, et al. Doppler echocardiographic index for assessment of global right ventricular function. JAm Soc Echocardiogr (1996) 9(6):838-47. doi:10.1016/S0894-7317(96)90476-9

64. Dyer KL, Pauliks LB, Das B, Shandas R, Ivy D, Shaffer EM, et al. Use of myocardial performance index in pediatric patients with idiopathic pulmonary arterial hypertension. J Am Soc Echocardiogr (2006) 19(1):21-7. doi:10.1016/j.echo. 2005.07.010

65. Patel N, Mills JF, Cheung MM. Use of the myocardial performance index to assess right ventricular function in infants with pulmonary hypertension. Pediatr Cardiol (2009) 30(2):133-7. doi:10.1007/s00246-008-9285-1

66. Forfia PR, Fisher MR, Mathai SC, Housten-Harris T, Hemnes AR, Borlaug BA, et al. Tricuspid annular displacement predicts survival in pulmonary hypertension. Am J Respir Crit Care Med (2006) 174(9):1034-41. doi:10.1164/rccm. 200604-547OC

67. Saxena N, Rajagopalan N, Edelman K, Lopez-Candales A. Tricuspid annular systolic velocity: a useful measurement in determining right ventricular systolic function regardless of pulmonary artery pressures. Echocardiography (2006) 23(9):750-5. doi:10.1111/j.1540-8175.2006.00305.x

68. Koestenberger M, Ravekes W, Everett AD, Stueger HP, Heinzl B, Gamillscheg A, et al. Right ventricular function in infants, children and adolescents: reference values of the tricuspid annular plane systolic excursion (TAPSE) in 640 healthy patients and calculation of $z$ score values. J Am Soc Echocardiogr (2009) 22(6):715-9. doi:10.1016/j.echo.2009.03.026

69. Ruan Q, Nagueh SF. Clinical application of tissue Doppler imaging in patients with idiopathic pulmonary hypertension. Chest (2007) 131(2):395-401. doi:10. 1378/chest.06-1556
70. Gurudevan SV, Malouf PJ, Kahn AM, Auger WR, Waltman TJ, Madani M, et al. Noninvasive assessment of pulmonary vascular resistance using Doppler tissue imaging of the tricuspid annulus. JAm Soc Echocardiogr (2007) 20(10):1167-71. doi:10.1016/j.echo.2007.02.004

71. De Castro S, Cavarretta E, Milan A, Caselli S, Di Angelantonio E, Vizza Carmine $\mathrm{D}$, et al. Usefulness of tricuspid annular velocity in identifying global RV dysfunction in patients with primary pulmonary hypertension: a comparison with 3D echo-derived right ventricular ejection fraction. Echocardiography (2008) 25(3):289-93. doi:10.1111/j.1540-8175.2007.00587.x

72. Rajagopalan N, Saxena N, Simon MA, Edelman K, Mathier MA, LopezCandales A. Correlation of tricuspid annular velocities with invasive hemodynamics in pulmonary hypertension. Congest Heart Fail (2007) 13(4):200-4. doi:10.1111/j.1527-5299.2007.06466.x

73. Patel N, Mills JF, Cheung MM. Assessment of right ventricular function using tissue Doppler imaging in infants with pulmonary hypertension. Neonatology (2009) 96(3):193-9; discussion 200-2. doi:10.1159/000215585

74. Motoji Y, Tanaka H, Fukuda Y, Ryo K, Emoto N, Kawai H, et al. Efficacy of right ventricular free-wall longitudinal speckle-tracking strain for predicting long-term outcome in patients with pulmonary hypertension. Circ J (2013) 77(3):756-63. doi:10.1253/circi.CJ-12-1083

75. Fine NM, Chen L, Bastiansen PM, Frantz RP, Pellikka PA, Oh JK, et al. Outcome prediction by quantitative right ventricular function assessment in 575 subjects evaluated for pulmonary hypertension. Circ Cardiovasc Imaging (2013) 6(5):711-21. doi:10.1161/CIRCIMAGING.113.000640

76. Smith BC, Dobson G, Dawson D, Charalampopoulos A, Grapsa J, Nihoyannopoulos $\mathrm{P}$. Three-dimensional speckle tracking of the right ventricle: toward optimal quantification of right ventricular dysfunction in pulmonary hypertension. J Am Coll Cardiol (2014) 64(1):41-51. doi:10.1016/j.jacc.2014.01.084

77. Kutty S, Deatsman SL, Nugent ML, Russell D, Frommelt PC. Assessment of regional right ventricular velocities, strain, and displacement in normal children using velocity vector imaging. Echocardiography (2008) 25(3):294-307. doi:10.1111/j.1540-8175.2007.00584.x

78. Levy PT, Sanchez Mejia AA, Machefsky A, Fowler S, Holland MR, Singh GK. Normal ranges of right ventricular systolic and diastolic strain measures in children: a systematic review and meta-analysis. J Am Soc Echocardiogr (2014) 27(5):549-60, e3. doi:10.1016/j.echo.2014.01.015

79. Berman GO, Reichek N, Brownson D, Douglas PS. Effects of sample volume location, imaging view, heart rate and age on tricuspid velocimetry in normal subjects. Am J Cardiol (1990) 65(15):1026-30. doi:10.1016/0002-9149(90) 91008-T

80. Pye MP, Pringle SD, Cobbe SM. Reference values and reproducibility of Doppler echocardiography in the assessment of the tricuspid valve and right ventricular diastolic function in normal subjects. Am J Cardiol (1991) 67(4):269-73. doi:10.1016/0002-9149(91)90558-3

81. Sallach JA, Tang WH, Borowski AG, Tong W, Porter T, Martin MG, et al. Right atrial volume index in chronic systolic heart failure and prognosis. JACC Cardiovasc Imaging (2009) 2(5):527-34. doi:10.1016/j.jcmg.2009.01.012

82. Yates AR, Welty SE, Gest AL, Cua CL. Myocardial tissue Doppler changes in patients with bronchopulmonary dysplasia. J Pediatr (2008) 152(6):766-70, 770.e1. doi:10.1016/j.jpeds.2007.11.039

83. Takatsuki S, Nakayama T, Jone PN, Wagner BD, Naoi K, Ivy DD, et al. Tissue Doppler imaging predicts adverse outcome in children with idiopathic pulmonary arterial hypertension. J Pediatr (2012) 161(6):1126-31. doi:10.1016/j. jpeds.2012.05.050

84. Okumura K, Slorach C, Mroczek D, Dragulescu A, Mertens L, Redington $\mathrm{AN}$, et al. Right ventricular diastolic performance in children with pulmonary arterial hypertension associated with congenital heart disease: correlation of echocardiographic parameters with invasive reference standards by high-fidelity micromanometer catheter. Circ Cardiovasc Imaging (2014) 7(3):491-501. doi: 10.1161/CIRCIMAGING.113.001071

85. Nagaya N, Satoh T, Uematsu M, Okano Y, Kyotani S, Nakanishi N, et al. Shortening of Doppler-derived deceleration time of early diastolic transmitral flow in the presence of pulmonary hypertension through ventricular interaction. Am J Cardiol (1997) 79(11):1502-6. doi:10.1016/S0002-9149(97) 00179-3

86. Schiller NB, Acquatella H, Ports TA, Drew D, Goerke J, Ringertz H, et al. Left ventricular volume from paired biplane two-dimensional echocardiography. Circulation (1979) 60(3):547-55. doi:10.1161/01.CIR.60.3.547 
87. Schiller NB, Shah PM, Crawford M, DeMaria A, Devereux R, Feigenbaum $\mathrm{H}$, et al. Recommendations for quantitation of the left ventricle by twodimensional echocardiography. American society of echocardiography committee on standards, subcommittee on quantitation of two-dimensional echocardiograms. J Am Soc Echocardiogr (1989) 2(5):358-67. doi:10.1016/ S0894-7317(89)80014-8

Conflict of Interest Statement: The authors declare that the research was conducted in the absence of any commercial or financial relationships that could be construed as a potential conflict of interest. The Review Editor Jeffrey Feinstein declares that despite having collaborated with author Dr D. Dunbar Ivy, the review process was handled objectively and no conflict of interest exists.
Received: 19 August 2014; accepted: 24 October 2014; published online: 12 November 2014.

Citation: Jone P-N and Ivy DD (2014) Echocardiography in pediatric pulmonary hypertension. Front. Pediatr. 2:124. doi: 10.3389/fped.2014.00124

This article was submitted to Pediatric Cardiology, a section of the journal Frontiers in Pediatrics.

Copyright (C) 2014 Jone and Ivy. This is an open-access article distributed under the terms of the Creative Commons Attribution License (CC BY). The use, distribution or reproduction in other forums is permitted, provided the original author(s) or licensor are credited and that the original publication in this journal is cited, in accordance with accepted academic practice. No use, distribution or reproduction is permitted which does not comply with these terms. 